\title{
A Study on Cognitive Emotion Regulation and Anxiety and Depression in Adults
}

\author{
Ms. Shefeena Jacob ${ }^{1 *}$, Dr. Milu Maria Anto ${ }^{2}$
}

\section{ABSTRACT}

The present study is an attempt to examine the relationship between cognitive emotion regulation strategies and anxiety and depression among adults. The rising prevalence of mental illness in today's world is mainly due to stress, tension or negative life experiences in our day to day life. In this regard, the way in which one's response to stress and negative life events may be more directly connected to mental health and psychopathology than the nature of stressful experience itself. A representative sample of 30 males and 30 females from Kottayam and Thrissur Districts of Kerala, of 20 - 40 years of age were selected. Cognitive emotion regulation questionnaire was administered to find out the cognitive emotion regulation strategies that participants use in response to the experience of stressful events. The inventory of Beck Depression Inventory -11 was distributed to find out the different symptoms of depression and State - Trait Anxiety Test was used to measure their state and trait anxiety levels. The results of Student t- test showed that, both males and females show significant differences in certain cognitive emotion regulation dimensions like positive appraisal, putting into perspective and other - blame and in depressive symptoms and in one of the anxietal symptom called Tension. And Co-efficient Correlation revealed that, self blame, catastrophizing, rumination and other blame were related with high level of depression and anxiety and subscales like acceptance, positive appraisal and putting into perspective were related with low levels of depression and anxiety. So the study concluded that there is relationship between cognitive emotion regulation strategies and anxiety and depression among adults. And also Cognitive Emotion Regulation Questionnaire (CERQ) has fit psychometric properties and could be used for clinical and investigative purposes.

Keywords: Cognitive Emotion Regulation; Anxiety; Depression

Early adulthood is a period marked by changes and growth physically, mentally and emotionally. It is a period of choosing new roles (husband, father, mother, wife etc) and establishing an identity congruent with those new roles. It involves asking and answering

\footnotetext{
${ }^{1}$ BSc. Psychology Student, Department of Psychology, Prajyoti Niketan College, Pudukad, Thrissur, Kerala

${ }^{2}$ Assistant Professor, Department of Psychology, Prajyoti Niketan College, Pudukad, Thrissur, Kerala *Responding Author

(C) 2016 I S Jacob, M Anto; licensee IJIP. This is an Open Access Research distributed under the terms of the Creative Commons Attribution License (http://creativecommons.org/licenses/by/2.0), which permits unrestricted use, distribution, and reproduction in any Medium, provided the original work is properly cited.
} 
questions "Who am I? And where am I going? The choices made during this time may be tentative, young adults may make several false starts.

During this period, people have to encounter with many stress and negative life situations. So many emotional problems will go through in their day to day life. It is necessary to cope with these negative life situations. Garnnefski \& Kraaig in 2006 referred in their research that, the way in which one responds to stress and negative life events may be more directly connected to mental health and psychopathology than the nature of the stressful experience itself. The concept of emotion regulation refers to this process, generally - the way in which an individual responds to and manages the negative emotions that accompany stressful experiences or events (Spinhoven, 2001). There are a, varieties of responses on which one draws, consciously or unconsciously to manage painful emotions, including physiological, cognitive and behavioral strategies.

According to Barlow in 2007, cognitive emotion regulation strategies are cognitive responses to emotion eliciting events that consciously or unconsciously attempt to modify the magnitude and/or type of individual's experiences or the event itself. To cope appropriately with these stress and negative life situations, cognitive emotion regulations are required. If a person fails to overcome these stress or negative emotions with cognitive emotion regulation, it will lead to psychopathological symptoms especially like anxiety and depression. The adaptive and maladaptive strategies of cognitive emotion regulation play an important role here. The adaptive strategies like acceptance, reappraisals, positive refocusing, refocus on planning etc leads to positive mental health outcomes, including decreased negative emotions, anxiety depression etc . [Gratz \& Roemer; 2004].The maladaptive strategies like self- blame, otherblame, rumination ,catastrophizing etc leads to poorer mental health.

In 2006, the Centers for Disease Control [CDC] found that 20.2\% of women surveyed have been diagnosed with depression compared with 8.2\% of men. In addition the WHO [2008] has reported the global rates of depression are $50 \%$ higher for women than for men. The sex differences in depression and anxiety might be artifacts of differences between men and women such as differences in sociometric status or levels of education or differences in the extent to which they acknowledge and seek help for their depression and anxiety, the level of encounter to negative life events, the ways people cope with stressful experiences.

A study conducted by Times of India in 2003, reported that, one of the every four Indians are affected by anxiety disorders and $10 \%$ are depressed. The rising prevalence of mental illness in the world has become a public health crisis with depression and anxiety represented the most common and debilitating psychiatric disorders. It is mainly due to the stress and tension we experience in our day to day life. So it has been argued that the way in which one responds to stress and negative life events may be more directly connected to mental health and psychopathology than the nature of the stressful experience itself. 
Thus the present study was conducted to study the impact of cognitive emotion regulation on anxiety and depression among adults with following objectives:

\section{OBJECTIVES}

1. To study the relationship between cognitive emotion regulation and anxiety and depression among adults.

2. To study the gender differences with respect to cognitive emotion regulation and anxiety and depression.

\section{METHOD}

\section{Samples}

The study was carried out in Kottayam \& Trichur districts of Kerala. The sample comprised of 30 males and 30 females in the age group of 20-40 years.

\section{Tools}

1. Cognitive Emotion Regulation Questionnaire [CERQ] developed by Nadia Garnefski, Vivian Kraaig \& Philip Spinhoven [2002] for measuring the cognitive emotion regulation strategies that subjects use in response to the experience of stressful life events.

2. State - Trait Anxiety Test [STAT] designed and developed bypsy.com services, Delhi [1991] to measure the state and trait anxieties if the participants.

3. Beck Depression Inventory - 11 [BDI - 11] developed by Anton T.Beck, Robert A. Steer \& Gregory K. Brown[1994] to assess the different symptoms of depression in the participants.

\section{Procedure}

The participants were contacted and explained about the purpose of the study. The three sets of questionnaires were administered to collect the data. Necessary instructions were given regarding the answering of test items. And the information obtained from them kept strictly confidential.

\section{Analysis Pattern}

In analysis of data, statistical procedures such as Student t- test and Coefficient Correlation were employed. 
RESULTS AND DISCUSSION

Table -1: Mean, Standard Deviation \& t-values of Males and Females in Cognitive Emotion Regulation Dimensions

\begin{tabular}{|c|c|c|c|c|c|c|}
\hline \multirow[t]{2}{*}{ S. No. } & \multirow{2}{*}{$\begin{array}{l}\text { Cognitive } \\
\text { Emotion } \\
\text { Regulation } \\
\text { Dimensions }\end{array}$} & \multicolumn{2}{|c|}{ Group $1(\mathrm{~N}=30)$} & \multicolumn{2}{|c|}{ Group $11(\mathrm{~N}=30)$} & \multirow[t]{2}{*}{ t-values } \\
\hline & & Mean & SD & Mean & SD & \\
\hline 1 & Self- blame & 10.46 & 1.86 & 9.07 & 3.15 & 1.47 \\
\hline 2 & Acceptance & 11.00 & 3.13 & 10.76 & 3.61 & 0.27 \\
\hline 3 & Rumination & 12.00 & 2.78 & 11.76 & 5.30 & 0.22 \\
\hline 4 & $\begin{array}{l}\text { Positive } \\
\text { refocusing }\end{array}$ & 13.00 & 4.32 & 13.76 & 3.49 & 0.74 \\
\hline 5 & $\begin{array}{l}\text { Positive } \\
\text { reappraisal }\end{array}$ & 14.9 & 2.57 & 13.26 & 3.47 & $2.05 *$ \\
\hline 6 & $\begin{array}{l}\text { Refocus on } \\
\text { planning }\end{array}$ & 14.76 & 3.65 & 14.5 & 3.8 & 0.26 \\
\hline 7 & $\begin{array}{ll}\text { Putting } & \text { into } \\
\text { perspective } & \\
\end{array}$ & 12.4 & 2.90 & 10.56 & 3.22 & $2.28 *$ \\
\hline 8 & catastrophizing & 9.3 & 3.51 & 8.63 & 2.69 & 0.82 \\
\hline 9 & Other-blame & 8.96 & 2.90 & 6.8 & 2.71 & $2.93 * *$ \\
\hline
\end{tabular}

Table -1 reveals that both the gender groups show significant difference in cognitive emotion regulation dimensions like positive reappraisal, putting into perspective and other-blame. Male shows higher response to cognitive emotion regulation strategies than females. It refers to the possibility that sex differences in response to cognitive emotion regulation might be artifacts to other differences between men and women such as differences in sociometric status or level of education or difference in the extent to which they acknowledge and seek help for their stress and negative life events. [Ingram, 1988]

Table - 2: Mean, Standard Deviation \& t-values of Males and Females in Depression.

\begin{tabular}{|l|l|l|l|l|l|}
\hline Dimension & \multicolumn{3}{|l|}{ Group $\mathbf{1}(\mathbf{N}=\mathbf{3 0})$} & Group 11 $\mathbf{( N = 3 0 )}$ & t - value \\
\hline \multirow{2}{*}{ Depression } & Mean & SD & Mean & SD & \multirow{2}{*}{.74** } \\
\cline { 2 - 5 } & 16.6 & 12.8 & 8.96 & 8.78 & \\
\hline
\end{tabular}

Table 2 indicates that both male and female groups significantly differ with respect to depression. Male group shows higher rates in depressive symptoms than female groups. An explanation refers here focuses on the ways people cope with stressful experiences. The higher levels of depressive and anxietal symptoms might be related to their less effective ways of coping. [Gross, 1999]. It is also argued that, the maladaptive strategies of cognitive emotion regulation like self -blame, other -blame, rumination, catastrophizing etc leads to psychopathology and poorer mental health. [Amelia Aldao \& Nolen - Hoeksema, 2010] 
Table - 3: Mean, Standard Deviation \& $t$ - values of Males and Females in State - Trait Anxiety

\begin{tabular}{|l|l|l|l|l|l|l|}
\hline \multirow{2}{*}{ S. No. } & \multirow{2}{*}{ Dimensions } & \multicolumn{2}{l}{ Group 1 $(\mathbf{N}=\mathbf{3 0})$} & \multicolumn{2}{l}{ Group 11 ( N = 30) } & \multirow{2}{*}{ - value } \\
\cline { 3 - 6 } & & Mean & SD & Mean & SD & \\
\hline 1 & Tension (Tn) & 9.00 & 3.80 & 6.86 & 3.03 & \multirow{2}{*}{$2.37^{*}$} \\
\hline 2 & Guilt Proneness (Gp) & 9.9 & 3.91 & 10.46 & 3.29 & 0.59 \\
\hline 3 & Maturity (Ma) & 4.2 & 2.41 & 4.5 & 3.44 & 0.38 \\
\hline 4 & Suspiciousness (Su) & 4.16 & 2.05 & 3.73 & 1.83 & 0.84 \\
\hline 5 & Self control (Sc) & 5.1 & 2.85 & 4.13 & 2.53 & 1.36 \\
\hline 6 & State anxiety (total) & 16.3 & 6.48 & 14.9 & 8.05 & 0.64 \\
\hline 7 & Trait anxiety (total) & 16.2 & 5.95 & 13.86 & 4.61 & 1.68 \\
\hline
\end{tabular}

Table 3 shows that both the gender groups differ significantly only on one dimension called Tension (Tn). Male shows higher rates in dimensions like Tension (Tn), Suspiciousness (Su), and Self control (Sc) when compared to females. Male also shows higher levels of state and trait anxiety than females. It might be the result of biological characteristics unique to them, for example: by hormonal or genetic predispositions [Nolen - Hoeksema, 1987]. An explanation says that, the encounter to negative life events and stressful life situations and that those are in turn related to the onset of anxiety and depression. It is also reported that, the use of maladaptive strategies might play a more central role in psychopathology than the non use of adaptive strategies. [Amelia Aldao, 2010].

Table 4: Correlation between Cognitive Emotion Regulation dimensions and Depression

\begin{tabular}{|l|l|l|}
\hline S. No. & $\begin{array}{l}\text { Cognitive Emotion Regulation } \\
\text { Dimensions }\end{array}$ & Depression \\
\hline 1 & Self - blame & $\mathbf{0 . 4 0}$ \\
\hline 2 & Acceptance & 0.09 \\
\hline 3 & Rumination & $\mathbf{0 . 2 5}$ \\
\hline 4 & Positive refocusing & $\mathbf{- 0 . 2 4 ^ { * }}$ \\
\hline 5 & Refocus on planning & $\mathbf{- 0 . 2 9}$ \\
\hline 6 & Positive reappraisal & -0.12 \\
\hline 7 & Putting into perspective & 0.05 \\
\hline 8 & Catastrophizing & $\mathbf{0 . 5 2}$ \\
\hline 9 & Other - blame & $\mathbf{0 . 4 7}$ \\
\hline
\end{tabular}

Table 4 reveals that, cognitive emotion regulation dimensions like self - blame, rumination, positive refocusing, refocus on planning, catastrophizing and other - blame shows significance with respect to depression. Depression is positively correlated to most of the dimensions like self - blame, rumination, catastrophizing, other - blame, acceptance and putting into perspective. It refers that self - blame, high extent of preoccupation with guilt can possibly be connected with symptoms of psychopathology and high levels $\mathrm{f}$ acceptance may refer to a negative form of resigning to the situation. [Garnefski \& et al, 2002]. Further, depression is negatively correlated to positive refocusing; refocus on planning and positive reappraisal. 
Table also indicates that depression varies negligibly with dimensions like acceptance, positive reappraisal, putting into perspective and slightly increases with rumination, positive refocusing and refocus on planning. It is also argued that the over response to adaptive strategies leads to poorer mental health [Garnefski \& et al, 2002]. And depression shows marked or substantial increase with dimensions like self - blame, catastrophizing and other - blame. An explanation refers to this is the unintended increase in negative thoughts has been shown to then lead to increase in symptoms of depression [Aldao \& et al, 2010].

Table 5: Correlation between Cognitive Emotion Regulation Dimensions \& State - Trait Anxiety.

\begin{tabular}{|l|l|l|}
\hline \multicolumn{1}{|c|}{$\begin{array}{c}\text { Anxiety } \\
\text { Dimensions }\end{array}$} & State anxiety & Trait Anxiety \\
CER Dimensions & & \\
\hline Self - blame & 0.17 & $\mathbf{0 . 4 0 ^ { * }}$ \\
\hline Acceptance & 0.13 & $\mathbf{0 . 3 1}$ \\
\hline Rumination & 0.14 & $\mathbf{0 . 6 3} *$ \\
\hline Positive refocusing & $\mathbf{- 0 2 9}$ & -0.12 \\
\hline Refocus on planning & $\mathbf{- 0 . 4 3 *}$ & -0.08 \\
\hline Positive reappraisal & -0.18 & 0.03 \\
\hline Putting into perspective & $\mathbf{- 0 . 2 1 *}$ & 0.04 \\
\hline Catastrophizing & $\mathbf{0 . 4 1 *}$ & $\mathbf{0 . 4 5}$ \\
\hline Other - blame & 0.16 & $\mathbf{0 . 4 3}$ \\
\hline
\end{tabular}

Table 5 indicates that State anxiety shows significance with cognitive emotion regulation dimensions like catastrophizing, positive refocusing, refocus on planning, putting into perspective and Trait anxiety shows with self - blame, rumination, catastrophizing, other blame and acceptance. The table further revealed that, state anxiety is positively correlated to dimensions like rumination, self - blame, other - blame, catastrophizing, and acceptance and negatively correlated to refocus on planning, positive refocusing and positive reappraisal. And trait anxiety is positively correlated to dimensions like self - blame, rumination , other - blame, catastrophizing, acceptance, putting into perspective and negatively correlated to positive refocusing and refocus on planning.

Table also shows that, state anxiety varies negligibly with dimensions like acceptance, positive reappraisal, self - blame, \& rumination and slightly increases with other - blame, positive refocusing, putting into perspective and markedly or substantially increases with catastrophizing and refocus on planning. It refers that the overuse of adaptive strategies of cognitive emotion regulation leads to psychopathology [Kraaig \& Spinhoven, 2002]. Further, trait anxiety shows negligible variation with most of the adaptive strategies like positive refocusing; refocus on planning, positive reappraisal and putting into perspective and shows slight increase with acceptance. And trait anxiety markedly or substantially increases with maladaptive strategies of 
cognitive emotion regulation like self - blame, other - blame, rumination and catastrophizing. It is also reported that self - blame, rumination, catastrophizing, other - blame, positive reappraisal were among the most valuable predictors of psychopathological symptoms and negative emotions [Eric \&Martin, 2005] and Cognitive Emotion Regulation Questionnaire (CERQ) has fit psychometric properties and could be used for clinical and investigative purposes [Majid Omran, 2011].

\section{CONCLUSION}

On the basis of above study, it can be said that males were found to be shown more responsive to cognitive emotion regulation strategies and depressive and anxiety symptoms than females. The above differences in males and females may be due to difference in Socio Economic Status (SES) or educational status or difference in the extent to which they seek help for their problems [Ingram, 1988]. Also males might be more likely to encounter adventurous life events than females. Further reason might be different cultural and familial expectations from males. In our society mostly males are the head, financial support and problem solver of the family.

It also focuses on the ways people cope with stressful experiences. The higher levels of depressive and anxietal symptoms might be related to their less effective ways of coping. [Gross, 1999]. The way in which individual manage and regulate emotion is central to mental illness. The response to maladaptive strategies and over response to adaptive strategies of cognitive emotion regulation plays a more central role in psychopathology. The adaptive and maladaptive strategies identified in the Cognitive Emotion Regulation Questionnaire (CERQ) have important clinical implications, has fit psychometric properties and could be used for clinical and investigative purposes. [Majid Omran, 2011]. Clinicians may it helpful to assist clients in finding a balance in the extent to which they focus on their distress.

\section{REFERENCES}

Ah Min, Jung \& Yu Jin; (2013). “Cognitive Emotion Regulation Strategies Contributing to Resilience in Patients with Depression \& Anxiety”, Psycho Linguo. Vol 39. pp 12 -16

Aldao, Amelio \&Nolen - Hoeksema; (2010). "Specificity of Cognitive Emotion Regulation Strategies - A trans diagnostic examination”. Behavior Research \& Therapy. Vol 48. pp 5-8

Barrat, E.S; (1965). Factor Analysis of Some Psychometric Measures of Impulsiveness \& Anxiety. Psychological Reports. Vol 16, pp $79-82$

Basharat, Amira \& Zubanb, Aisha; (2005). "Psychological distress and coping strategies among families of missing persons in Pakistan”. Pakistan Journal of Psychological Research. Vol 1(2)

Ben dig, A.W; (1960). "Factor analysis of anxiety \& neuroticism inventories". Journal of Consulting Psychology. Vol 24 (2). Pp 3 - 6 
Garnefski, Nadia; (2002). "Cognitive Emotion Regulation Strategies \& Depressive Symptoms difference between males \& females”. Journal of Personality \& Individual Differences. Vol 36. pp $25-29$

Hamilton, M; (1959). "The assessment of anxiety states by rating”. British Journal of medical Psychology. Vol 22

Hamilton, M; (1960). “A rating scale for depression”. Journal for Neurology \& Neurosurgical Psychiatry. Vol 23. pp $13-21$

Martin, B; (1959). “The measurement of anxiety”. Journal of General Psychology. Vol 61

Martin, R.C \& Dahlen, E.R; (2005). "Cognitive Emotion Regulation in the Prediction of Depression, anxiety, stress \& anger”. Journal of personality \& Individual differences. Vol 39. pp $34-40$

Omran, M. Pourfaraj; (2011). "Relationship between cognitive emotion regulation strategies with depression and anxiety". Open journal of Psychiatry. Vol 37. pp $76-81$

Reavley, W; (1974). "The relationship of life events to several aspects of anxiety". Journal of Psychomatic Research. Vol 18(6). pp 87 - 91

Sadock, J. B \& Sadock, A.V; (2007). Synopsis of Psychiatry. Ed (10). Lippincott Williams \& Wilkins. New York. P - 379 